\title{
PROGRAMA DE EDUCACION DE PADRES PARA EL DESARROLLO INTEGRAL DEL NIÑO EN UNA COMUNIDAD MARGINADA
}

\section{Planteamiento del problema}

Si se tiene en cuenta que de la atención que se le da al individuo en sus primeras etapas de evolución, depende el adecuado desarrollo y su desenvolvimiento futuro dentro de la comunidad, la Universidad Pedagógica Nacional ha tenido a bien llevar a cabo un programa, centrado en la relación familia-individuo, con el fin de incrementar el desarrollo integral del niño durante sus tres primeros años de vida, a través de la educación de la familia.

Examinando algunos trabajos como: "Estudio Etnográfico de una comunidad y su escuela" realizado por Muñoz y Col. 1976, se encontró que la población en edad preescolar, constituía aproximadamente el $20.9 \%$ de la población (un total de 408 ); la escuela no ofrece programas de atención dirigidos a niños menores de 6 años, situación que se agrava por el hecho de que el $22 \%$ de las mujeres de la comunidad realizan trabajos remunerados, y el $78 \%$ aun cuando están "dedicadas al hogar" deben cumplir tareas que las obligan a salir constantemente de su casa. Por esta razón, la mayor parte de los niños en edad preescolar, permanecen solos o al cuidado de sus hermanos mayores.

Por otra parte, la observación lograda por el equipo de investigación durante el último trimestre de 1975, en 19 Centros Infantiles de Bogotá, señala una situación crítica en esta área de educación, puesto que la proporción de población atendida es mínima, las condiciones de atención son poco favorables y no existen currículos sistematizados; además hay pocas personas calificadas en educación preescolar (Ramírez y Col., 1975).

La ausencia de programas o currículos dirigidos a la población responsable del cuidado del niño, la deficiente preparación del personal encargado de la educación pre-escolar y la necesidad de lograr un modelo aplicable a otras comunidades y guarderías con características socio-económicas similares, justifican el programa si consideramos los beneficios que puede reportar.

\section{Objetivos}

A través del programa se busca:

1. Incorporar y comprometer a los padres de comunidades marginadas para que participen en programas encaminados a promover el desarrollo integral del niño.

2. Elaborar y evaluar un currículo sobre el desarrollo del niño de 0-36 meses, obteniendo así un modelo que pueda ser utilizado en la educación de madres de comunidades marginadas y en la formación de auxiliares o cuidadoras dedicadas a la atención de los niños en las instituciones.

\section{Metodología}

La técnica empleada será la audiovisual, y dentro de esta modalidad se utilizará el fotomontaje, el cual presenta algunas de las siguientes características: Puede emplearse en poblaciones tanto letradas como iletradas, sus costos son reducidos, el material es de 
fácil traslado y su manejo facilita el aprendizaje, condiciones que permiten que sea un modelo generalizable a poblaciones con características similares.

Con el objeto de desarrollar contenidos del currículo de manera que no se presente un desfase entre éstos y la situación vivida en la comunidad, se llevaron a cabo las siguientes actividades: Una encuesta, en la cual se exploraron aspectos del contenido de las unidades; charlas con 6 madres y observaciones en 6 familias para refinar las unidades y enriquecer sus contenidos. Para el primer año de vida se diseñaron cuatro unidades básicas: Salud, Higiene - Vestido y Alimentación, todas encaminadas a mejorar el desarrollo general del niño y la unidad de Interacción familia-niño que enfatiza el papel que aquélla debe desempeñar en el enriquecimiento de un ambiente que favorezca al niño.

El currículo para el desarrollo del niño de 2 y 3 años, se elaborará siguiendo la misma metodología.

El grupo de personas que recibirá el curso, estará compuesto inicialmente por las madres de los niños menores de un año, del barrio El Codito, haciéndose extensivo al $2^{\circ}$ y $3^{\circ}$ año de vida. Habrá una etapa de motivación individual a través de contactos personales con cada madre. Posteriormente, se buscará una integración y motivación del grupo, empleando diferentes formas de interacción.

Después de la proyección de cada unidad, habrá una discusión en subgrupos de 5 ó 6 personas con el fin de lograr una mayor comunicación. Después de cada discusión se tendrán reuniones en grupo con el fin de realizar una síntesis y sacar conclusiones generales.

Para la aplicación de los aspectos contemplados en cada unidad se prestará una asesoría directa a las madres; ésta se realizará a través de visitas periódicas a la vivienda y de la participación de las madres en los cursos.

Se emplearán diferentes formas de evaluación: Una evaluación formal que determine la claridad del currículo y su forma de presentación; una evaluación de la efectividad del currículo, para determinar si las madres aplican los aspectos contemplados en cada una de las unidades del currículo a la situación de hogar; y una evaluación de contenido, para determinar si la aplicación de los contenidos del curso por parte de la madre, produce algún efecto en el desarrollo del niño.

Grupos de Control: Con el objeto de obtener datos comparativos, se tendrán dos grupos de control en poblaciones con características similares. El primero, estará constituido por niños que reciben atención médica y suplemento alimenticio, pero cuyas madres no recibirán el programa educativo; el segundo, por un grupo de niños que no recibieran ningún programa.

Mediante la comparación de los tres grupos, se pretende controlar el efecto del programa educativo para madres en el desarrollo de los niños, así como la obtención de datos que permitan comparar el desarrollo de los niños que reciben y no reciben suplemento alimenticio.

\section{Complementos del programa:}

Una casa del barrio será "La Casa del Niño", centro alrededor del cual girarán todas las actividades encaminadas a fomentar el desarrollo del niño pre-escolar. 
Nutrición: En la casa se preparará el suplemento alimenticio, el cual se distribuirá a todos los niños que se encuentren viviendo el primer año de vida y posteriormente se hará extensivo al $2^{\circ}$ y $3^{\circ}$ año.

Se considera que para que los niños aprovechen plenamente los programas de interacción familia-niño encaminados a fomentar un mejor desarrollo, es necesario suministrar un suplemento alimenticio que cubra el déficit nutricional de la dieta habitual del niño en la comunidad.

Salud: Este programa también será desarrollado en "La Casa del Niño" y estará a cargo de una enfermera calificada. Considerando que estos niños presentan una alta propensión a enfermedades, y que una enfermedad durante estos primeros años o perjudica en su desarrollo, el programa contemplará medidas tanto preventivas como curativas.

Recreación: Esta actividad será desarrollada por una maestra de pre-escolar, quien tendrá a su cargo la promoción de los programas de interacción familia-niño.

Adelantos de la investigación

En este momento se encuentran elaborados los guiones de las cuatro unidades básicas: Salud, Higiene - Vestido, Alimentación e interacción familia-niño para el primer año de vida. Además, se está realizando el fotomontaje de la parte introductoria del curso, y la primera unidad del programa. 